\title{
Hydrolytic degradation of nitrendipine and nisoldipine
}

\author{
A. Álvarez-Lueje *, J. Sturm, J.A. Squella, L.J. Núñez-Vergara \\ Bioelectrochemistry Laboratory, Chemical and Pharmaceutical Sciences Faculty, University of Chile, P.O. Box 233, \\ Santiago 1, Chile
}

\begin{abstract}
The development of a new HPLC-UV diode array procedure applied to follow the hydrolytic degradation of two well-known 4-nitrophenyl-1,4-dihydropyridine derivatives, nitrendipine and nisoldipine is reported. Hydrolysis of each drug were carried out in ethanol/Britton-Robinson buffer at different $\mathrm{pHs}$, stored into amber vials at controlled temperatures of 40,60 and $80{ }^{\circ} \mathrm{C}$ and periodically sampled and assayed by HPLC. Nitrendipine degradation in different parenteral solutions was also evaluated. The HPLC procedure exhibited an adequate selectivity, repeatability $(<1 \%)$ and reproducibility $(<2 \%)$. The recoveries were higher than $98 \%$ with $\mathrm{CV}$ of 1.13 and $1.54 \%$ for nitrendipine and nisoldipine, respectively. A significant degradation was observed at alkaline $\mathrm{pH}(>\mathrm{pH} 8)$ with a first order kinetic for both drugs. At $\mathrm{pH} 12,80^{\circ} \mathrm{C}, k$ values of $3.56 \times 10^{-2} \mathrm{~h}^{-1}$ and $2.22 \times 10^{-2}$ for nitrendipine and nisoldipine, respectively were obtained. Also, activation energies of 16.8 and $14.7 \mathrm{kcal} \mathrm{mol}^{-1}$ for nitrendipine and nisoldipine, respectively, were calculated. Furthermore, from the results obtained from hydrolytic degradation in different solutions for parenteral use, we can affirm that solutions significantly increased the degradation of nitrendipine. In conclusion, the HPLC proposed procedure exhibited adequate analytical requirements to be applied to the hydrolytic degradation studies of nitrendipine and nisoldipine. Furthermore, all tested parenteral solutions significantly increased the hydrolytic degradation of nitrendipine, the composition of solution being a relevant factor.
\end{abstract}

Keywords: HPLC; Degradation; 1,4-dihydropyridines; Hydrolysis; Parenteral solutions; Kinetic constants

\section{Introduction}

Calcium antagonist drugs are a therapeutic class widely used in different cardiovascular conditions such as hypertension and angina pectoris $[1,2]$. Chemically, are represented by the 1,4-dihydropyridine group, being such pentasubstituted

* Corresponding author. Fax: + 56-737-8920.

E-mail address: aalvarezl@entelchile.net (A. Álvarez-Lueje). nucleus the pharmacophore. Normally, these substitutions include a lipophilic ring in 4-position, short alkyl chain groups in both 2 and 6 positions and ester functions with variable alkoxy length chains in both 3 and 5 positions. The pharmacological activity depends on both, the integrity of the chemical structure and the stereochemistry, which must be retained to develop the optimal interaction with the receptor and thus get the pharmacological and therapeutic efficacy. Obvi- 
ously all changes in the pharmacophore induces changes in its pharmacological or toxicological properties [3].

For these reasons the study of drug stability acquires an important pharmaceutical relevance, and is an important factor to determine both efficacy and toxicity. Commonly it is not enough to know the drug amount declared in pharmaceuticals, but is desirable to know if degradation occurred and the kind of the degradation products [4]. Taking into account that as a consequence of drug degradation generally minimal chemical changes are produced, selective analytical tools for the quantification and/or identification of the degradation products are required. Consequently, developing analytical procedures that permit the selective determination of both, the 1,4-dihydropyridine compounds and its degradation products are an interesting challenge for a pharmaceutical analytical chemist.

Considering the relevance of drug stability on the therapeutic efficacy, in this work the hydrolytic degradation of two calcium antagonist drugs, widely used in cardiovascular therapy, as nitrendipine and nisoldipine (Fig. 1) is studied.

There are a lot of works related with analytical procedures devoted to determine 1,4-dihydropyridine compounds. This type of drugs has been assayed in biological fluids by GC with electroncapture [5,6], nitrogen detection [7], mass spectrometric detection [8-10], HPLC with UV [11-13], electrochemical [14-16] and amperometric detection [17]. Furthermore, screening techniques have been carried out for several 1,4-dihydropyridine drugs. Daylight degradation products using GCMS [18] and the chemical stability and pharmacokinetics in rabbits of amlodipine by HPLC-UV have been informed [11]. The pharmaceutical form analysis includes mainly HPLC [18-20] and voltammetric techniques [21-23].

On the other hand, there are some works related with stability studies involving photodecomposition of, nisoldipine assessed by UV derivative spectrophotometric technique [24], inclusion complexes of isradipine with methyl- $\beta$-cyclodextrin [25], nifedipine in powder [26] and nifedipine in selected pharmaceutical preparations [27]. Also, the effects of photodegradation products of nifedipine in dog erythrocyte membranes [28] and our previous electrochemical studies on nisoldipine [29], nitrendipine [30], furnidipine [31] and nicardipine [32] have been reported.

Up to day, literature does not report systematic studies about the hydrolytic degradation of 1,4-dihydropyridines in a whole range of $\mathrm{pH}$ or in solutions of different compositions. Nevertheless there are some studies devoted to degradation of 1,4-dihydropyridine drugs, such as amlodipine, isradipine and nicardipine in simulated pharmaceutical forms [33-35], but these studies did not contain information about kinetic parameters. Moreover, recently HPLC coupled with mass spectrometry technique has been used to try to establish the identity of a number of degradation products from a bulk drug form of isradipine at different experimental conditions [36].

In this work we are reporting about a new HPLC procedure useful to study the stability of

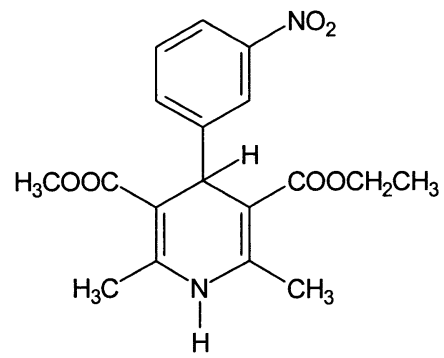

NITRENDIPINE<smiles>CC(=O)C1=C(C)NC(C)=C(C(=O)OCC(C)C)C1c1ccccc1[N+](=O)[O-]</smiles>

NISOLDIPINE

Fig. 1. Chemical structures of the 1,4-dihydropyridine drugs. 
nitrendipine and nisoldipine. This procedure has been successfully applied to the quantitative assessment of the hydrolytic degradation kinetic of these drugs at different $\mathrm{pH}$ and media conditions.

These types of studies could give basic information to support the feasibility of a possible presystemic degradation due to the extreme $\mathrm{pH}$ conditions of the gastro-intestinal tract, considering that these drugs are commonly administered by oral route. Furthermore, this type of studies also could provide a useful knowledge to developed new oral liquid dosage forms.

\section{Experimental}

\subsection{Reagents and drugs}

Nitrendipine and nisoldipine (100\% chromatographically pure) were obtained from Bayer and Labomed Laboratories (Santiago, Chile), respectively. All other reagents employed were of analytical or HPLC grade. The water was double distilled and deionized (Milli-Q quality).

Glucose 5 and 10\%, Ringer-lactate, glucosaline and physiologic solutions supplied by Sanderson Laboratories (Santiago, Chile) were used as the parenteral pharmaceutical vehicles.

\subsection{Buffer solutions}

Solutions for the HPLC studies were buffered using a $0.05 \mathrm{M}$ buffer phosphate solution (disodium hydrogen phosphate anhydrous salt) adjusted at $\mathrm{pH} 3$ with phosphoric acid. Degradation trials were carried out using $0.04 \mathrm{M}$ BrittonRobinson buffer (acetic acid/boric acid/phosphoric acid) adjusted to the desired $\mathrm{pH}$ with $\mathrm{NaOH}$ solutions.

\subsection{Apparatus}

\subsubsection{High performance liquid chromatography (HPLC)}

HPLC measurements were carried out by using a Waters assembly equipped with a 600 model Controller pump and a 996 model Photodiode Array Detector. The acquisition and treatment of data were made by means of the Millenium version 2.1 software. As chromatographic column a $\mu$ Bondapak/Porasil C-18 column, 10- $\mu$ m-particle size $(3.9 \mathrm{~mm} \times 150 \mathrm{~mm})$ and as column guards a C18 $\mu$ Bondapak $(30 \mathrm{~mm} \times 4.6 \mathrm{~mm})$ were employed. The injector was a $20 \mu \mathrm{L}$ Rheodyne valve.

\subsection{Mobile phases}

For nitrendipine a gradient elution composed by a solution consisting of acetonitrile-phosphate buffer ( $\mathrm{pH} \mathrm{3;} 50 \mathrm{mM})(37: 63, \mathrm{v} / \mathrm{v})$ was used. The following linear gradient was used: $9.5 \mathrm{~min}$ isocratic elution with this mobile phase at $2 \mathrm{ml}$ $\min ^{-1}$ and then a gradient program with increasing flux of $0.1 \mathrm{ml} \mathrm{min}{ }^{-1}$ for $5 \mathrm{~min}$. The working temperature was $35^{\circ} \mathrm{C}$.

For nisoldipine a gradient elution composed by methanol-phosphate buffer $(\mathrm{pH} 3 ; 50 \mathrm{mM})$ in a gradient program starting from a 20:80 v/v mobile phase ratio with a linear gradient for $10 \mathrm{~min}$ to reach 40:60 v/v and then a new linear gradient for $15 \mathrm{~min}$ to obtain a final ratio of $60: 40 \mathrm{v} / \mathrm{v}$ of the mobile phase in a total time of $35 \mathrm{~min}$ at a constant temperature of $37{ }^{\circ} \mathrm{C}$ was used. The flux was kept constant at $1.5 \mathrm{ml} / \mathrm{min}$.

\subsection{Degradation trials}

Buffer solutions were spiked with nitrendipine or nisoldipine to obtain initial concentrations ranging between $5.0 \times 10^{-4}$ to $9.0 \times 10^{-4} \mathrm{M}$ and $1.0 \times 10^{-2}$ to $1.0 \times 10^{-4} \mathrm{M}$ for each drug, respectively. The solutions were divided in a number of amber vials of $2 \mathrm{ml}$ (one for each point of the degradation curve) and the vials placed in a heater at $80.0 \pm 0.2{ }^{\circ} \mathrm{C}$. Vials were removed from the heater at selected time intervals, immediately cooled in ice to quench the reaction, and kept in the freezer until HPLC analysis when it was necessary. Prior to HPLC analysis, solutions were diluted 1:10 with $50 \mathrm{mM}$ phosphate buffer $\mathrm{pH} 3$ when it was necessary.

Degradation was monitored over at least three half-lives. Experiments were carried out in duplicate. 

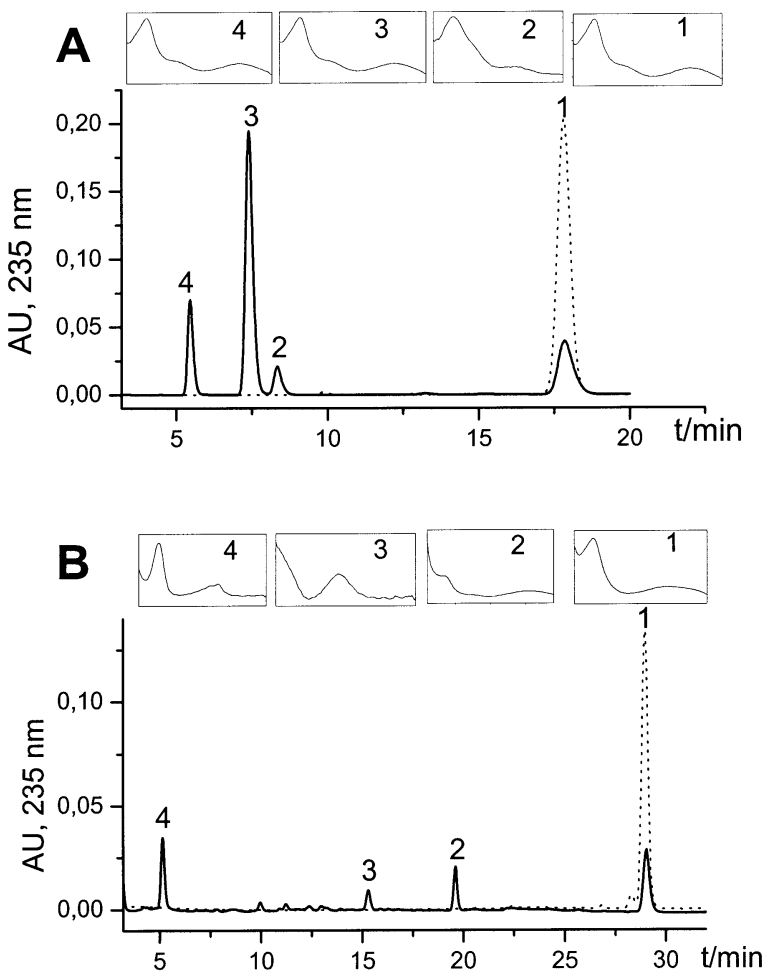

Fig. 2. HPLC chromatograms of (A) nitrendipine and (B) nisoldipine at $235 \mathrm{~nm}$. Standard (dashed line) and after alkaline hydrolysis (solid line). 1: Parent drug, 2-4: hydrolytic products. Insert: normalized UV spectra for each signal $(\lambda=$ $200-400 \mathrm{~nm})$

\subsection{Hydrolysis}

$5.0 \times 10^{-4} \mathrm{M}$ solution of each drug were prepared in ethanol-0.04 $\mathrm{M}$ Britton-Robinson buffer (30:70) varying the $\mathrm{pH}$ with $\mathrm{NaOH}$ or $\mathrm{HCl}$. Each solution was divided into amber vials of 2 $\mathrm{ml}$, hermetically sealed and stored at constant temperature $\left(40,60\right.$ or $\left.80{ }^{\circ} \mathrm{C}\right)$, periodically sampled and assayed by HPLC.

\subsection{Degradation in parenteral solutions}

The same protocol was followed for each drug, but the $\mathrm{pH}$ was not adjusted, maintaining the $\mathrm{pH}$ of the parenteral solution, which varied according to the following: Ringer-lactate $\mathrm{pH}$ 7.4, Physiologic solution $\mathrm{pH} 7.2$, Glucosaline solution $\mathrm{pH}$ 6.4, 5\% Glucose pH 6.9 and 10\% Glucose $\mathrm{pH} 7.1$.

\subsection{Statistic analysis}

Comparison between different techniques, as well as the comparison with standard deviations, were carried out by means of the Student's $t$-test, and using significance limits between 95 and $99 \%$ of confidence [37,38].

\section{Results and discussion}

In this work a new analytic procedure to follow the hydrolytic degradation of two 1,4-dihydropyridine drugs, nitrendipine and nisoldipine (Fig. 1) is proposed.

Typical HPLC chromatograms of each parent drug and its hydrolytic degradation products in optimal chromatographic conditions are shown in Fig. 2. The optimal conditions were a programmed linear gradient elution containing acetonitrile-phosphate buffer ( $\mathrm{pH} 3 ; 50 \mathrm{mM})$ (37:63, $\mathrm{v} / \mathrm{v}$ ) for nitrendipine and methanol-phosphate buffer ( $\mathrm{pH} 3 ; 50 \mathrm{mM}$ ) for nisoldipine, as described in detail in the experimental section.

As can be seen from Fig. 2 and Table 1, in the optimal chromatographic conditions retention

Table 1

Retention times $\left(t_{\mathrm{r}}\right)$ of 1,4-dihydropyridine drugs $(\lambda=235 \mathrm{~nm})$

\begin{tabular}{|c|c|c|c|c|}
\hline & \multicolumn{2}{|l|}{ Nitrendipine } & \multicolumn{2}{|l|}{ Nisoldipine } \\
\hline & Standard & Hydrolysis products & Standard & Hydrolysis products \\
\hline$t_{\mathrm{r}}(\min )$ & $17.84 \pm 0.56$ & $\begin{array}{l}5.48 \pm 0.09 \\
7.38 \pm 0.06 \\
8.34 \pm 0.13\end{array}$ & $28.86 \pm 0.15$ & $\begin{array}{r}4.87 \pm 0.08 \\
14.94 \pm 0.33 \\
19.34 \pm 0.09\end{array}$ \\
\hline
\end{tabular}



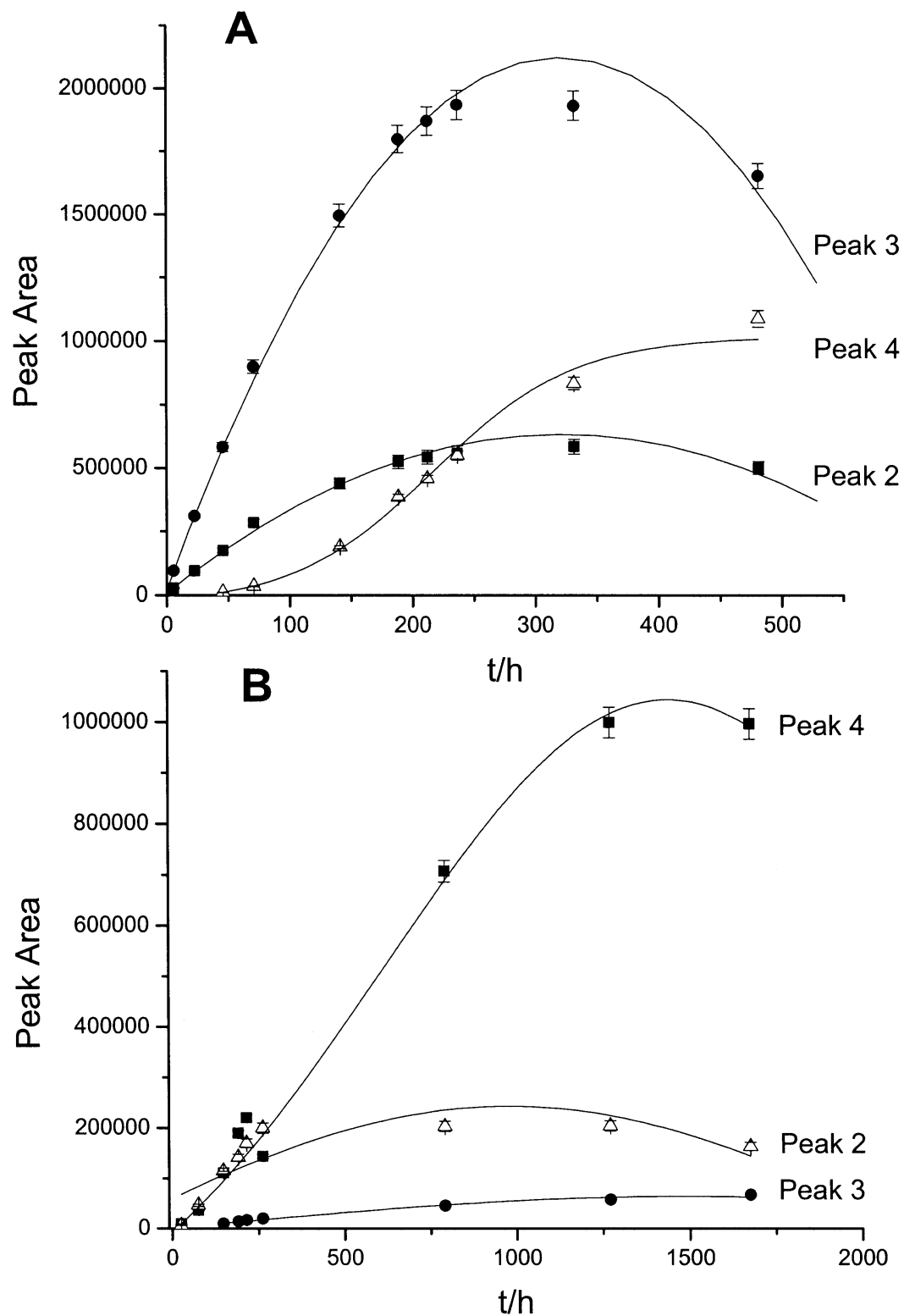

Fig. 3. Time-course of hydrolytic products from (A) nitrendipine and (B) nisoldipine at $5 \times 10^{-5} \mathrm{M}$ and $\mathrm{pH} 10$.

times for hydrolytic products were significantly lower than those of the parent drugs. In the case of nisoldipine, such retention times were significantly different between them. However, for nitrendipine the difference was light. This results could be explained based on the nature of the substituents, thus nitrendipine possesses methoxy, ethoxy- groups on the carbonyl moiety versus methoxy-, isobutoxy- groups for nisoldipine. Consequently, these structural differences could confer different lipophilic characteristics at each hydrolytic product, producing these different retention times.

As expected, parallel with the time-course of the hydrolysis, a decrease of the original peak corresponding to the parent drugs occurred with- 
out any interference with other signals. Thus, the developed method becomes sufficiently selective to discriminate each drug and their corresponding hydrolytic products, being a useful tool to follow this type of degradation. Data of Fig. 2 correspond to a 78 and $84 \%$ degradation after $48 \mathrm{~h}$ of

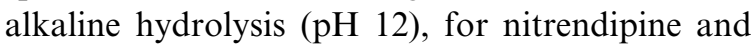
nisoldipine, respectively. In conclusion, retention time values of $17.84 \pm 0.56$ and $28.86 \pm 0.15 \mathrm{~min}$ in the optimal experimental conditions for nitrendipine and nisoldipine respectively, were obtained.

Fig. 3 shows the time-course of the hydrolytic products during 20 and 75 days for nitrendipine and nisoldipine respectively, at $80{ }^{\circ} \mathrm{C}$ and $\mathrm{pH} 10$. As can be seen from this figure, in the case of nitrendipine (A) the hydrolytic product with $t_{\mathrm{r}}=$ 7.38 min (peak 3) was formed at higher quantity than the other products. Likewise, the hydrolytic product of nisoldipine (B) with $t_{\mathrm{r}}=4.78 \mathrm{~min}$ (peak 4) has the same behavior. In both cases the shape of the plots were similar, a rapid increase of the main products and then their decrease, probably due to generation of other hydrolysis products or the final product, the diacid derivative (data not shown).

Table 2

Analytical parameters of the HPLC method

\begin{tabular}{|c|c|c|}
\hline Parameter & Nitrendipine & Nisoldipine \\
\hline $\begin{array}{l}\text { Repeatability, } \\
\text { CV }(\%)^{\mathrm{a}}\end{array}$ & 0.56 & 0.79 \\
\hline $\begin{array}{l}\text { Reproducibility, } \\
\text { CV }(\%)^{\mathrm{a}}\end{array}$ & 0.83 & 1.23 \\
\hline Recovery $(\%)^{\mathrm{b}}$ & 99.0 & 98.7 \\
\hline $\begin{array}{l}\text { Concentration } \\
\text { range }(\mathrm{M})\end{array}$ & $1 \times 10^{-5}-1 \times 10^{-4}$ & $1 \times 10^{-5}-1 \times 10^{-4}$ \\
\hline $\begin{array}{l}\text { Calibration } \\
\text { curve }^{c}\end{array}$ & $\begin{array}{l}Y=1.1583 \times 10^{10}, \\
{[X]-20843.6} \\
(r=0.9995)\end{array}$ & $\begin{array}{l}Y=1.6501 \times 10^{10}, \\
{[X]-2828} \\
(r=0.9991)\end{array}$ \\
\hline $\begin{array}{l}\text { Detection limit } \\
\text { (M) }\end{array}$ & $1.82 \times 10^{-7}$ & $2.1 \times 10^{-7}$ \\
\hline $\begin{array}{l}\text { Quantitation } \\
\text { limit (M) }\end{array}$ & $2.0 \times 10^{-6}$ & $3.2 \times 10^{-6}$ \\
\hline
\end{tabular}

${ }^{\text {a }}$ Concentration level of $5 \times 10^{-5} \mathrm{M}$.

${ }^{\mathrm{b}}$ Average on a concentration level of $5 \times 10^{-5} \mathrm{M}$.

c $Y=$ peak area, $X=$ molar concentration.
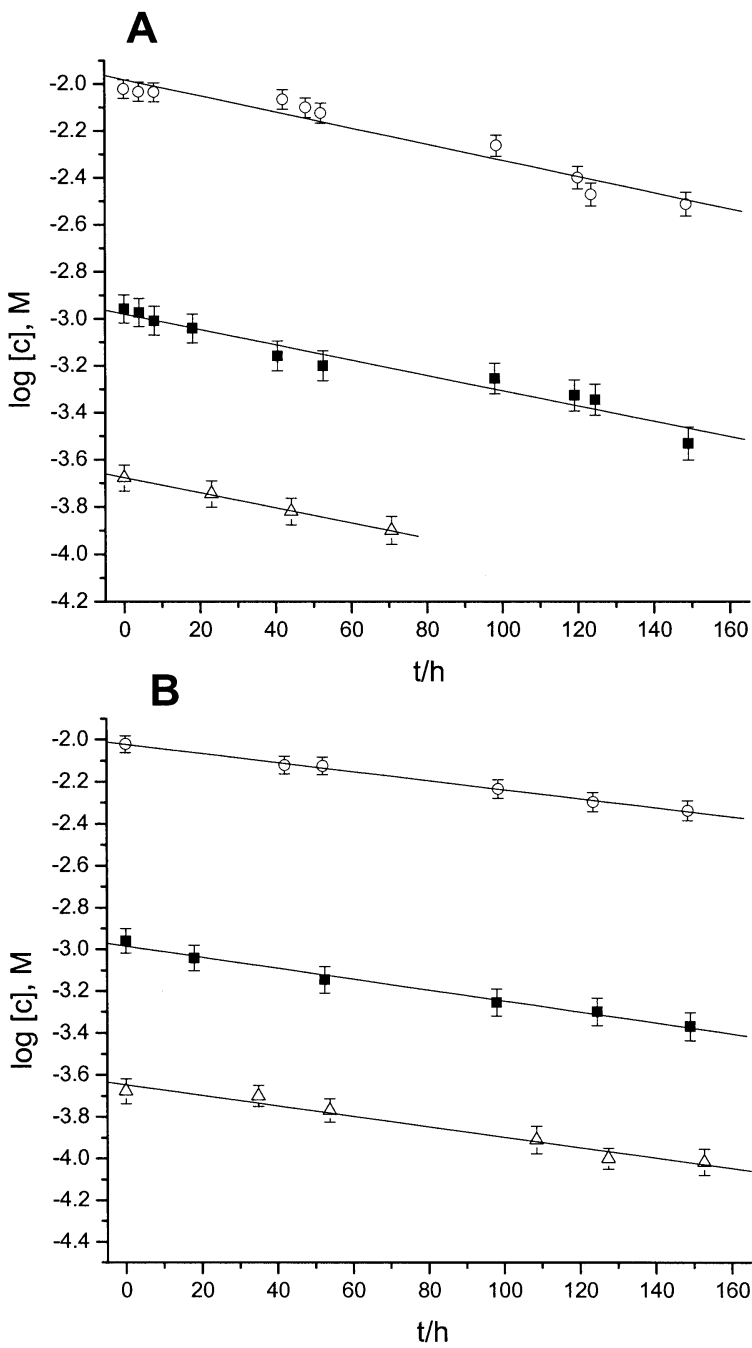

Fig. 4. Decay plots of: (A) nitrendipine and (B) nisoldipine at different initial concentration and $40{ }^{\circ} \mathrm{C}$ temperature, $\mathrm{pH} 12$ $\left(\bigcirc, 9.5 \times 10^{-3} \mathrm{M} ; \boldsymbol{\square}, 1.1 \times 10^{-3} \mathrm{M} ; \triangle, 2.1 \times 10^{-4} \mathrm{M}\right)$

In Table 2, the analytical assessment of the new HPLC procedure for both drugs is summarized. From the obtained analytical parameters it can be concluded that the method fulfils analytical requirements with an adequate repeatability $(<1 \%)$ and reproducibility $(<2 \%)$. The recoveries were higher than $98 \%$ with CV of 1.13 and $1.54 \%$ for nitrendipine and nisoldipine, respectively. On the other hand, concentration ranges for calibration curves seem to be adequate to follow degradation with detection and quantitation average 
limits about $1.96 \times 10^{-7}$ and $2.6 \times 10^{-6} \mathrm{M}$, respectively.

The developed HPLC methodology was applied to follow the hydrolytic kinetic degradation of the 1,4-dihydropyridine drugs. For the analytical application, hydrolytic studies in the whole range of $\mathrm{pH}$ were conducted. However, only at $\mathrm{pH}>8$ detectable degradation was found.

To test the kinetic order of the hydrolytic degradation, experiments varying both initial concentration and $\mathrm{pH}$ were performed. As can be seen from Fig. 4, changes in the initial concentration did not affect the slopes of the decay curves. Consequently, from both the linearity of plots log $c$ versus $t$ and the fact that slopes of such plots remain unaltered, a first order kinetic for the hydrolytic degradation for these drugs can be
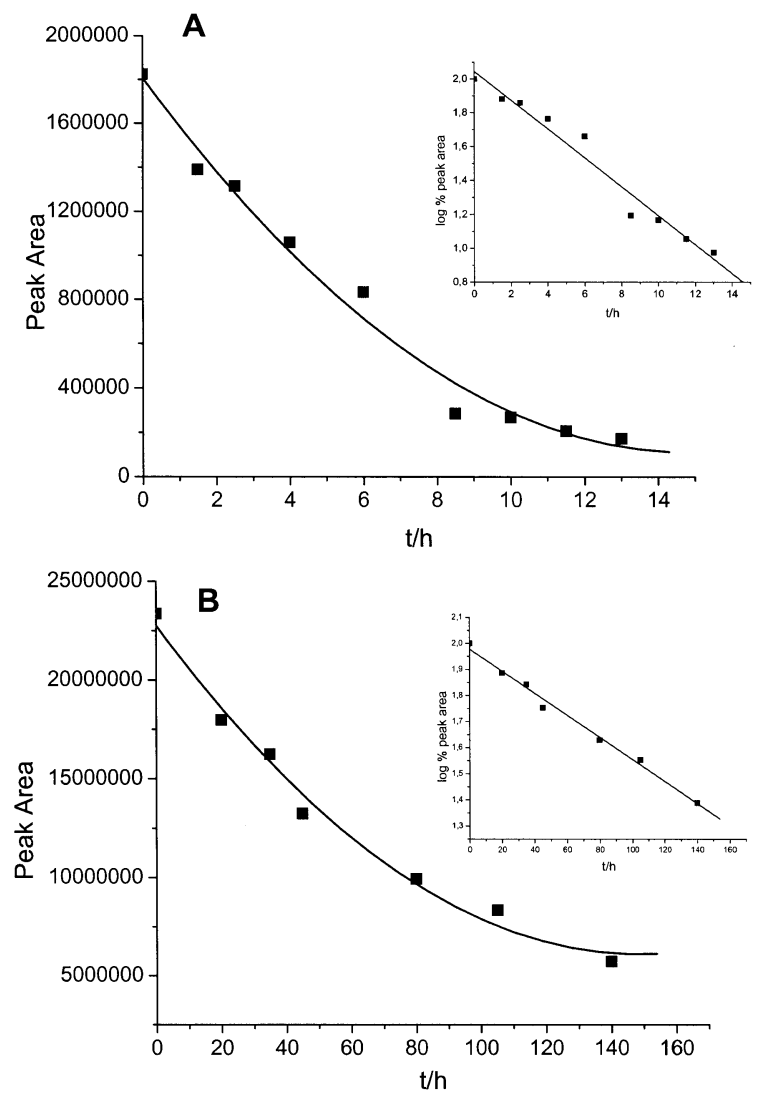

Fig. 5. First order decay plot for: (A) nitrendipine and (B) nisoldipine in Britton-Robinson buffer at $1 \times 10^{-4} \mathrm{M}$ and at controlled temperature of $80{ }^{\circ} \mathrm{C}$.

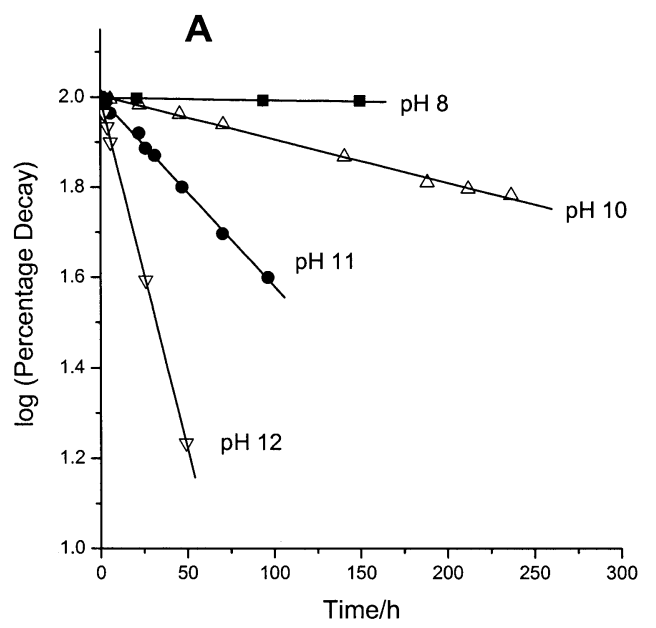

B

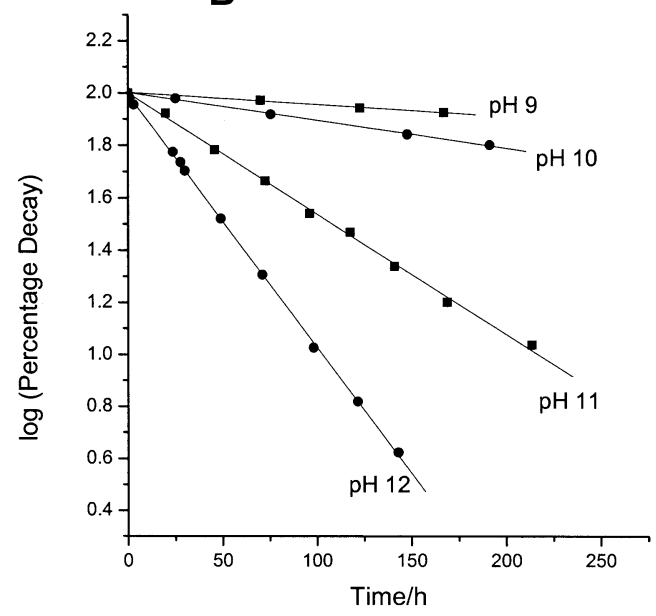

Fig. 6. Decay plots at different $\mathrm{pH}$ of: (A) nitrendipine; and (B) nisoldipine at $80{ }^{\circ} \mathrm{C}$.

assumed [4]. In Fig. 5 typical decay plots for nisoldipine and nitrendipine in Britton-Robinson buffer at $\mathrm{pH} 12$ and a controlled temperature of $80{ }^{\circ} \mathrm{C}$ with their corresponding linearization are shown.

In Fig. 6 the decay plots at different $\mathrm{pH}$ are shown. As can be seen, from $\mathrm{pH} 8$ the hydrolytic degradation of both drugs is notoriously increased with $\mathrm{pH}$, but the magnitude of the calculated constants for both drugs do not differ significantly between them, nitrendipine being slightly more labile than nisoldipine in these hydrolytic conditions. Furthermore, from the behavior of the calculated decay constants with $\mathrm{pH}$, represented 
in Fig. 7, it can be concluded that only at $\mathrm{pH} 12$ differences between decay constant values for nitrendipine and nisoldipine were apparent, with decay constant values of $3.56 \times 10^{-2}$ and $2.22 \times$ $10^{-2} \mathrm{~h}^{-1}$, respectively.

Additionally, experiments at different temperatures were conducted. From the Arrhenius plots, activation energies of 16.8 and $14.7 \mathrm{kcal} \mathrm{mol}^{-1}$ for nitrendipine and nisoldipine, respectively were calculated. These values are in agreement with

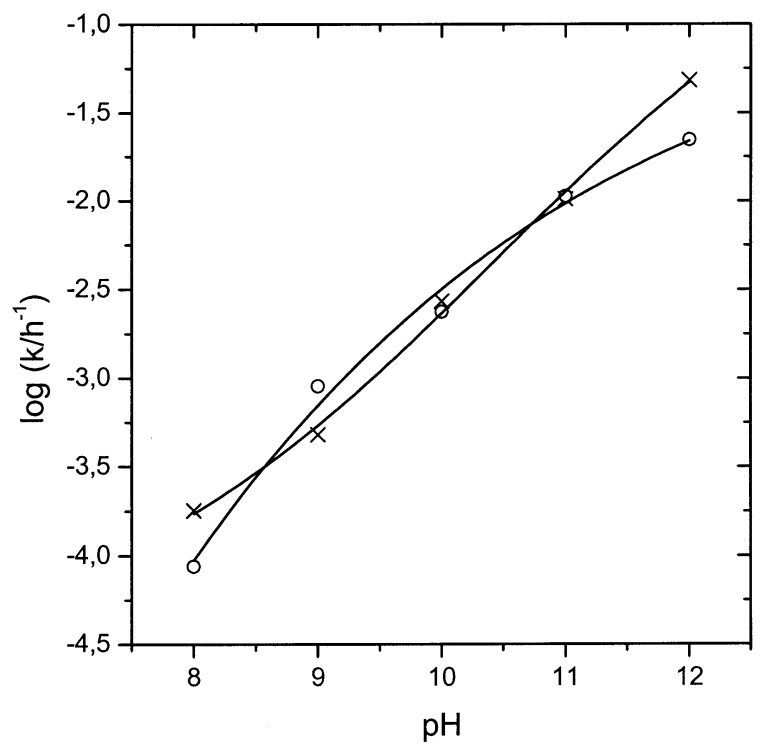

Fig. 7. Evolution of decay constant with $\mathrm{pH}$ for nitrendipine $(\times)$ and nisoldipine $(\bigcirc)$ obtained at $80{ }^{\circ} \mathrm{C}$.

Table 3

Influence of different pharmaceutical vehicles on the hydrolytic degradation of nitrendipine (calculated at $80{ }^{\circ} \mathrm{C}$ temperature)

\begin{tabular}{|c|c|c|}
\hline Formulation & $k\left(\mathrm{~h}^{-1}\right) \times 10^{2}$ & $k_{\text {formulation }} / k_{\text {control }}{ }^{a}$ \\
\hline Ringer-lactate (pH 7.4) & 0.649 & 48.1 \\
\hline $\begin{array}{l}\text { Physiologic solution } \\
\text { (pH 7.2) }\end{array}$ & 0.679 & 50.3 \\
\hline $\begin{array}{l}\text { Glucosaline solution } \\
\text { (pH 6.4) }\end{array}$ & 1.253 & 92.8 \\
\hline 5\% Glucose (pH 6.9) & 1.455 & 107.8 \\
\hline $10 \%$ Glucose $(\mathrm{pH} 7.1)$ & 1.552 & 115.0 \\
\hline
\end{tabular}

\footnotetext{
a Ratio of $k$ nitrendipine in parenteral solution versus $k$ in Britton-Robinson buffer $\mathrm{pH} 8\left(k=0.0135 \times 10^{-2} \mathrm{~h}^{-1}\right)$.
}

those reported for different drugs containing ester groups in their structure [4]. Interestingly, extrapolated $t_{90}$ values at $25{ }^{\circ} \mathrm{C}$ and $\mathrm{pH} 12$ of 177 and 205 days for nitrendipine and nisoldipine, respectively were obtained [4].

In order to test the catalytic effects of wellknown parenteral solutions on the hydrolytic degradation of this type of drugs, 5 and $10 \%$ glucose, Ringer-lactate, glucosaline and physiologic solutions were tested for nitrendipine. Comparisons between hydrolytic degradation in buffer solutions and in the above described pharmaceutical vehicles at the normal $\mathrm{pH}$ of these preparations ( $\mathrm{pH}$ 6.4-7.4) were carried out. Surprisingly these results show that the presence of the parenteral solutions, significantly increased the hydrolytic degradation of nitrendipine compared with those obtained in Britton-Robinson buffer at $\mathrm{pH} 8.0$ (Table 3). It is necessary to remark that $\mathrm{pH} 8$ was the minor $\mathrm{pH}$ in which the degradation phenomenon was observed in this buffer solution.

Furthermore, degradation of nitrendipine was increased 48.1-fold in Ringer-lactate solution compared with normal buffer $\mathrm{pH} 8$ and in the extreme case, an increase of 115-fold in the rate of degradation in the presence of $10 \%$ glucose solution compared with control, was noted. In general terms, these results would indicate that the increase in the rate of degradation when changing from Britton-Robinson buffer solution to parenteral solutions, depends on the composition rather than the $\mathrm{pH}$ solution.

\section{Conclusions}

1. The HPLC proposed method exhibited adequate analytical requirements of repeatability, reproducibility, accuracy and selectivity to be applied to the hydrolytic degradation studies of nitrendipine and nisoldipine.

2. At the best of our knowledge, no studies on the hydrolysis of nitrendipine and nisoldipine have been reported in literature, therefore the present study appears to be relevant for these two 1,4-dihydropyridines of therapeutic importance. In addition, considering that ester 
groups at 3- and 5-positions are essential to its pharmacological activity, the degradation products generated by the hydrolysis would lack of therapeutic activity [3].

3. All tested parenteral solutions increased the hydrolytic degradation of nitrendipine over the range of 6-7. Thus, when compared with Britton-Robinson buffer solutions at the same $\mathrm{pH}$, the composition of the solution appeared to be a relevant factor.

\section{Acknowledgements}

Authors are very grateful with the support of FONDECYT Grant No 1990964.

\section{References}

[1] C. Libersa, R. Bordet, J. Caron, L. Guedon-Moreau, Therapie 50 (1995) 101-108.

[2] R.J. de Vires, D.J. van Veldhuisen, P.H. Dunselman, Am. Heart J. 139 (2000) 185-194.

[3] S. Goldmann, J. Stoltefuss, Angew. Chem. 30 (1991) 1559-1578.

[4] K.A. Connors, C.L. Amidon, V.J. Stella, Chemical Stability of Pharmaceuticals: A Handbook for Pharmacist, J. Wiley, New York, 1986.

[5] P.A. Soons, M.C. Roosemalen, D.D. Breimer, J. Chromatogr. 528 (1990) 343-356.

[6] N. Watari, J. Mizumura, S. Higuchi, J. Chromatogr. 530 (1990) 438-446.

[7] M.T. Rosseel, M.G. Bogaert, L. Huyghens, J. Chromatogr. 533 (1990) 224-228.

[8] K.S. Patrick, E.J. Jarvi, A.B. Straughn, M.C. Meyer, J. Chromatogr. 495 (1989) 123-130.

[9] J. Martens, P. Banditt, F.P. Meyer, J. Chromatogr. B. Biomed. Appl. 660 (1994) 297-302.

[10] J.D. Dru, J.Y. Hsieh, B.K. Matuszewski, M.R. Dobrinska, J. Chromatogr. Biomed. Appl. 666 (1995) 259-267.

[11] P.K. Yeung, S.J. Mosher, P.T. Pollak, J. Pharm. Biomed. Anal. 9 (1991) 565-571.

[12] M. Gabrielsson, K.J. Hoffmann, C.G. Regårdh, J. Chromatogr. 573 (1992) 265-274.

[13] J. Luksa, D. Josíc, B. Podobnik, B. Furlan, M. Kremser, J. Chromatogr. B Biomed. Sci. Appl. 693 (1997) 367-375.

[14] M. Josefsson, B. Norlander, J. Pharm. Biomed. Anal. 15 (1996) 267-277.
[15] F. Barbato, B. Capello, L. Grumetto, P. Morrica, Farmaco. 48 (1993) 417-426.

[16] V. Horváth, A. Hrabéczy-Páll, Z. Niegreisz, E. Kocsi, G. Horvai, L. Gödörházy, A. Tolokán, I. Klebovich, K. Balogh-Nemes, J. Chromatogr. B Biomed. Appl. 686 (1996) 211-219.

[17] J.A. López, V. Martínez, R.M. Alonso, R.M. Jiménez, J. Chromatogr. A. 870 (2000) 105-114.

[18] F. Barbato, L. Grumetto, P. Morrica, Farmaco. 49 (1994) $461-466$.

[19] United States Pharmacopoeia XXIII/NF XVIII. United States Pharmacopoeial Convention, Inc., Rockville M.D. USA, pp. 1083, 1084 (1995).

[20] British Pharmacopoeia 1999. CD-ROM v. 3.0, The Stationery Office, United Kingdom (1999).

[21] A. Álvarez-Lueje, L.J. Núñez-Vergara, J.A. Squella, Electroanalysis 5 (1994) 259-264.

[22] J.A. Squella, A. Iturriaga, A. Álvarez-Lueje, L.J. NúñezVergara, Electrochem. Soc. Proc. 97-19 (1997) 376-386.

[23] J.A. Squella, J.C. Sturm, R. Lenac, L.J. Núñez-Vergara, Anal. Lett. 25 (1992) 281-292.

[24] V. Marinkovic, D. Agbaba, K. Karljikovic-Rajic, J. Comor, D. Zivanov-Stakic, Farmaco. 55 (2000) 128-133.

[25] J. Mielcarek, E. Daczkowska, J. Pharm. Biomed. Anal. 21 (1999) 393-398.

[26] N. Hayase, Y. Itagaki, S. Ogawa, S. Akutsu, S. Inagaki, Y. Abiko, J. Pharm. Sci. 83 (1994) 532-538.

[27] A. Bogdan, T. Kaniewska, Acta Pol. Pharm. 54, (1997) 261-266.

[28] N. Hayase, Y. Itagaki, S. Akutsu, S. Inagaki, Y. Abiko, Yakugaku Zasshi 117 (1997) 202-210.

[29] A. Álvarez-Lueje, L. Naranjo, L.J. Núñez-Vergara, J.A. Squella, J. Pharm. Biomed. Anal. 16 (1998) 853-862.

[30] J.A. Squella, A. Zanocco, S. Perna, L.J. Núñez-Vergara, J. Pharm. Biomed. Anal. 8 (1990) 43-47.

[31] L.J. Núñez-Vergara, C. Sunkel, J.A. Squella, J. Pharm. Sci. 83 (1994) 502-507.

[32] J.A. Squella, Y. Borges, C. Celedón, P. Peredo, L.J. Núñez-Vergara, Electroanalysis 3 (1991) 221-225.

[33] M.C. Nahata, R.S. Morosco, T.F. Hipple, J. Am. Pharm. Assoc. 39 (1999) 375-377.

[34] J.L. MacDonald, C.E. Johnson, P. Jacobson, Am. J. Hosp. Pharm. 51 (1994) 2409-2411.

[35] D.M. Baaske, J.F. DeMay, C.A. Latona, S. Mirmira, K.W. Sigvardson, Am. J. Health Syst. Pharm. 53 (1996) $1701-1705$.

[36] M.G. Bartlett, J.C. Spell, P.S. Mathis, M.F. Elgany, B.E. El Zeany, M.A. Elkawy, J. Pharm. Biomed. Anal. 18 (1998) 335-345.

[37] R.C. Graham, Data Analysis for the Chemical Sciences. A Guide to Statistical Techniques, VHC Publishers, Inc, 1993, pp. 105-146.

[38] J.K. Taylor, Statistical Techniques for Data Analysis, Lewis Publishers, Inc., pp.65-79, 165-166 (1990). 